\title{
The impact of entrepreneurial leadership and learning orientation on organizational perfor- mance of SMEs: The mediating role of innovation capacity
}

\author{
Fahad Awad Aber Sawaean ${ }^{a^{*}}$ and Khairul Anuar Mohd Ali ${ }^{\mathrm{b}}$
}

${ }^{a}$ Researcher, UKM-Graduate School of Business, National University of Malaysia, 43600 Bangi, Selangor, Malaysia ${ }^{b}$ UKM-Graduate School of Business, National University of Malaysia, 43600 Bangi, Selangor, Malaysia

\section{H R O N I C L E}

\section{Article history:}

Received: July 92019

Received in revised format: July

192019

Accepted: August 25, 2019

Available online:

August 25, 2019

Keywords:

Entrepreneurial Leadership

Learning orientation

Innovation capacity

Organizational Performance

\section{A B S T R A C T}

Kuwait's SMEs contribute to the economic growth of the country by creating productive jobs for Kuwaiti youth and professionals and improving income diversification. SMEs in Kuwait are faced with numerous challenges and these problems must be addressed to achieve and ensure longer-term success and better performance. This paper seeks to examine the relationship between the determinants of organizational performance such as entrepreneurial leadership (EL), learning orientation (LO), and innovation capacity (IC) of Kuwaiti's Small and Medium Enterprises (SMEs). The study used a quantitative method. A survey questionnaire was administered to gather the data, where the useable data was obtained from 384 of the 500 SME owners and CEOs in Kuwait. The outcomes of this study indicate that entrepreneurial leadership and learning orientation had positive and significant implication on organizational performance. Moreover, the innovation capacity is also found to be a significant mediator in the relationships.

O 2020 by the authors; licensee Growing Science, Canada

\section{Introduction}

Small and Medium Enterprises (SMEs) are of strategic importance in many developing countries, particularly those in the Asian region (Haroon \& Shariff, 2016). SMEs are major contributor to the economic growth of a country through the creation of employment opportunities and promotion of technological innovation; additionally, SMEs provide support for entrepreneur activities and serve as suppliers to large organizations in the industry. They play an important role not only as a catalyst, but also as a key driver towards achieving an inclusive and balanced growth. SMEs form the fundamentals of activities in the private sector and are therefore very important in the economic transformation process. They also serve as growth stabilizer during period of negative growth (Yunoh \& Ali 2015). In contemporary era, SMEs are confronted with intense competitive pressure. SMEs must enhance their competitive abilities and skills in order to be able to survive and ensure continuous longterm development. There are several tools and strategies that can help SMEs respond to changes and deal with threats whilst improving their performance and competitive advantage (Kraśnicka et al., 2016; Yang, 2018).

SMEs need to understand how entrepreneurial leadership could affect organizational performance (Rahim et al., 2015). Entrepreneurial leadership is the way in which entrepreneurial leaders restructure organizations in order to capitalize on new opportunities and improve organizations' competence to create the requisite variety which enables them to compete in a highly unpredictable environment (Huang et al., 2014). Entrepreneurs are expected to modernize the design of production process through creative practices or by manufacturing existing products using novel methods; this is done by exploring untapped sources of materials or by creating new outlets for products and services (Zehir, et al., 2015). To be able to do these things, entrepreneurial leaders should adopt specific management philosophies and methods which allows for the integration of * Corresponding author. Tel.: + 96566213352

E-mail address: zp03485@siswa.ukm.edu.my (F.A.A. Sawaean) 
knowledge to be utilized in new processes, products, and operational activities (Gupta \& Batra, 2016). In general, learning orientation is the evolution of new knowledge or insights which could influence behaviour through ideas and values. Learning orientation involves acquiring, disseminating and applying knowledge; it is an effective mechanism for generating new ideas which create the ability to carry out innovation in organisations (Allameh \& Khalilakbar, 2018). SMEs are now focusing on making innovation by virtue of its crucial role in achieving a stable competitive advantage. Innovation is commonly perceived as an essential requirement for the sustainability and success of an organization. In terms of the formulation and adoption of new ideas or behaviours by organizations, innovation can begin with a new, service, product, method of production or a new market, and organizational structure or administrative system (Lestari et al., 2018).

A better comprehension of the dynamics between entrepreneurial leadership, learning orientation, and innovation capacity is essential in order to be able to examine and analyse how these variables influence organizational performance. The rationale for carrying out this study originates from the literature review which shows that there is a dearth of empirical studies that provide insights into the interdependence of the variables in this study in the context of developing countries particularly in Kuwait's SMEs.

\section{Literature Review}

\subsection{Entrepreneurial Leadership}

The $21^{\text {st }}$ century brings with it the opening of world economy and the accompanying challenges which has led to the business environment shifting its focus to entrepreneurial leadership (Mishra \& Misra, 2017). The owners and leaders of SMEs must be cognizant of the changes taking place in the global business environment. There is no business which can survive and succeed without a clear vision established by the organization's leadership and supported by entrepreneurial actions. In order to do this, leaders of organizations, whether they are CEOs, directors or operation managers, must understand their own capabilities, competencies and leadership styles and what they desire to ultimately achieve. They must be proactive, creative, innovative, capitalize on opportunities, and take risks when necessary. Intelligent leaders of organizations use their skills and capabilities to the fullest to achieve growth and rapid development for their firms whilst creating competitive advantage and sustainable businesses (Palalic, 2017). The theory of entrepreneurship states that the personal competencies of entrepreneurial leaders enable them to envision a successful future for their organizations; they can formulate innovative visions and identify opportunities. On the other hand, the functional competencies of entrepreneurial leaders empower them to inspire and influence their team members to abandon conventional performance in carrying out their tasks and amplify their efforts in implementing innovation and entrepreneurial actions; this is achieved by transforming individuals' perceptions of their abilities and skills and maximizing their self-efficacy by involving them in development and training programs (Bagheri, 2017).

Entrepreneurial leadership encourages and enables organizations to adopt processes that reinforce the culture of organizational innovation by discovering and capitalizing on opportunities to improve organizational performance, solve problems using creative methods, and utilize the resources of the organization effectively and efficiently (Rae, 2017). Greenberg et al. (2011) define entrepreneurial leaders as individuals who understand themselves and the contexts of the working environment and stand up to manipulate opportunities to create values for their organizations and stakeholders as well as for the whole society. Chen (2007) pointed out that entrepreneurial leadership exists at the crossroads of leadership and entrepreneurship; it is a combined construct of proactivity, innovation, and risk-taking. This perspective is congruent with the theoretical foundation developed by Gupta et al (2004) for this style of leadership, where the authors conceptualized entrepreneurial leadership in three main dimensions: (1) innovation dimension, which means reinforcing creativity among team member in making effective change and creating novel products and services to obtain a competitive advantage for the organization; (2) proactive dimension which involves motivating individuals to compete aggressively and continuously with other organizations; and (3) risk-taking dimension which is the willingness to face uncertainty and take responsibility (Kozlowski, 2010).

The goal of entrepreneurial leadership is to empower individuals to identify and exploit fruitful opportunities. In a similar vein, Strobl et al. (2018) proposed that entrepreneurial leadership includes both, opportunity recognition, which is related to individual's perception and exploitation of opportunities, which in turn is linked with action. Entrepreneurial leaders articulate a vivid and inspiring vision for their organizations that can garner participation of individuals, thereby enhancing their awareness to act as an agent of the organization in charge of innovation and future success.

Gupta et al. (2004) theorized that entrepreneurial leadership is centered on two major challenges that entrepreneurial leaders must deal with. They contended that the first challenge faced by entrepreneurial leaders is scenario enactment, where they are required to bring into existence an environment of possible opportunities to reconstruct current situation. The second challenge, cast enactment, involves persuading stakeholders and followers that it is possible to achieve the goals of the scenario by recruiting additional cast and utilizing appropriate resources to execute the transformation. Gupta et al. (2004) pointed out that there are five important things that entrepreneurial leaders must do in dealing with these challenges: framing, absorbing uncertainty, clearing the path, building commitment, and setting limits. These roles under fall under the two dimensions of enactment and form the abstract framework for entrepreneurial leadership. 
Based on literature review, the researchers find that, entrepreneurial leadership is a multidimensional concept. Previous researchers defined and measured entrepreneurial leadership based on different perspectives depending on the context and purpose of their study. The present study includes four dimensions of entrepreneurial leadership, i.e. visionary, opportunity seeking, proactivity, and risk-taking propensity).

\subsection{Learning Orientation}

Since the last several decades, researchers have been focusing on entrepreneurial and learning orientations. Learning orientation is conceived as a fundamental attitude towards learning and reflects the role of managers and organizations in encouraging organizational learning processes. In a similar vein, learning orientation is seen as organizational values which influence organization's propensity to generate and utilize knowledge (Amin, 2015; Hurley \& Hult, 1998).

Kalmuk and Acar (2015) suggested that organizations need to employ individuals who are capable of acquiring and discerning novel technological developments and market information from the outside environment. Additionally, members of organizations must have the competency and talent to process information effectively whilst creating new knowledge at a more rapid rate than their rivals. Learning orientation in organizations is linked with their strategic renewal. Hence learning orientation is currently perceived as a means for achieving continuous competitive advantage; it has also achieved equal importance as innovative productivity in innovative literature. In summary, learning orientation influence individual performance as much as it affects organizational performance.

Learning orientation is the mastering of knowledge and skills by means of study and experience. It is an essential operational resource as it allows organizations to maintain their competitive advantage by continuously developing their capacity to manipulate market information more rapidly than their competitors (Vij \& Farooq, 2015). Organizations that are more proficient at introducing, acquiring, and transferring knowledge and that can reorientation their behavior to demonstrate the new knowledge are more capable of responding to a rapidly evolving dynamics in a turbulent business environment (Tajeddini, 2016). Sinkula et al (1997, p. 309) defined learning orientation as organizational culture which determined the propensity of organizations to construct and implement knowledge. This implies that, in addition to short episodes of organizational training and development, learning orientation requires the cultivation of a new organizational culture which comprises new values, norms, beliefs, assumptions, and expected behavior (Baba, 2015).

Learning orientation helps the management develop their abilities to question the validity and effectiveness of current values, beliefs, and practices which are supposed to ensure the performance of an organization. It reinforces the learning norms in an organization and encourages employees to acquire new knowledge in order to increase organizational capabilities to achieve superior performance. Hence, learning orientation improve the learning behavior of an organization and transform organizational culture into a more advanced market and entrepreneurial oriented culture which ensure long term growth and survival (Hussain et al., 2018). Sinkula et al. (1997) conceptualized learning orientation as a set of values which determine the extent to which an organization is satisfied with the theories being adopted by proactively evaluating their current principles and practices which affect their organizational performance. In this context, the present study adopts the scale recommended by Sinkula et al. (1997), which include a set of core values for measuring and evaluating the learning orientation adopted by organizations. The scale comprises four dimensions, i.e. commitment to learning, shared vision, open mindedness, and intraorganizational knowledge sharing. But this study was ruled out the dimension of intra-organizational knowledge sharing.

\subsection{Innovation Capacity}

Innovation is the most contemporary management orientation; it refers to the ability of organizations to create and develop new ideas and transform these ideas into a processes, products and services. According to Şimşit et al. (2014), innovation is a continuous process for developing productive resources which are then employed to manufacture existing products with superior quality at lower cost. Along the same line, Ilori et al. (2017) defined innovation as implementing new knowledge into processes, products, and services. The authors categorised innovation according to technological development, marketing activities, and organizational characteristics. Based on the definitions given, innovation is a sequential process which begins with recognition of a problem or discovery of a novel idea and is followed by problem-solving and the creation of productive ability to introduce creative products and services in the market.

Innovation does not occur spontaneously. This is because the intense competition in global environment requires that organizational authorities coordinate, facilitate, and make the decision to be innovative. Innovation depends on a strong crossfunctional orchestration. This orchestration requires for the structuring of teams and delegation of responsibilities, roles, and powers as a part of the effort to meet the innovation challenge. Consequently, organizations must have a suitable organizational structure with clear commitment to innovation (Nagano et al., 2014). Oura et al. (2015) pointed out that measurement of innovation capacity is a complex process considering that innovation capacity, as a construct, consists of several dimensions, including (1) R\&D capacity, (2) learning capacity, (3) manufacturing capacity, (4) marketing capacity, (5) organisational capacity, (6) strategic capacity, and (7) resource exploitation capacity. These constructs, as well as other dimensions, of innovation capacity have a positive effect on performance of SMEs.

The entrepreneurship theory states that the competitive ability of an organization is dependent upon innovation. The ability to innovate is contingent upon organization's capacity to effectively deal with existing and future problems in the business 
environment. In addition, innovation should consider the fundamentals of development and utilization of new technologies (Meyer \& Paulsen, 2018). Once sustainable growth has been achieved, organizations are compelled to innovate and increase their capacity to meet new requirements by introducing different services, products, and processes. Hence, organizations exert themselves to improve and develop innovative skills, create sustainable capabilities and improve their organizational performance (Dereli, 2015).

\subsection{Organizational Performance}

Organizational performance is one of the most significant dependent variables that has attracted the interest of researchers who are concerned with any area of management since it is only through performance that organizations are able to progress and grow (Jagdale \& Bhola, 2015). Ahmed (2018) defined organizational performance as a combined system of organization's output in the light of its interaction with external and internal environment. Thus, organizational performance comprises three aspects: (1) individual's performance within their specialized organizational units; (2) performance of organizational units inside the comprehensive framework policies of an organization; and (3) organizational performance within the framework of economic, cultural and social environment. Even though organizational performance comprises these three aspects, it is completely different from each individual aspect when considered separately. It is different from individual performance and unit performance despite the fact it is the result of both factors in addition to the effects of social, economic and cultural environment.

There are different philosophies and definitions of organizational performance. Performance is the essence of all processes and activities in organizations and it determines the survival of an organization. Wheelen and Hunger (2010) contended that organizational performance is a manifestation of the way organizations make the most of tangible and intangible resources to accomplish their objectives and is the pinnacle of an organization's efforts. Tomal and Jones (2015) argued that organizational performance as the actual results or output of an organization as oppose to its intended outputs. Furthermore, Almatrooshi et al. (2016) suggested that organizational performance is the achievement of an organization as distinguished from its objectives. The contingency theory states that, in general, there is no single proper performance measurement system that can be used for all types of organizations under all circumstances; instead the system must be adapted based on specific organizational and contextual factors. According to the literature there are several performance indicators, such as financial performance, increasing market share, effective marketing, innovation process, quality of products and services that measure various dimensions of operational performance. Based on the findings and results of previous studies, two indicators (financial performance and operational performance) will be used in the present study to measure the performance of Kuwait's SMEs.

Financial performance is the ability of an organization to generate profit or income. It is frequently employed to gauge how an organization conduct its business activities as well as its business results. It can also be used to weigh the performance of one organization against another within an industry. These measures relate to the method used by the management to allocate funds for various projects. Specifically, they reflect internal managerial performance and decision-making capability instead of a reflection of external market response (Orlitzky et al., 2003). Chavan (2009) reprimanded SMEs for relying too much on financial performance measures without considering non-financial measures which are the real drivers of value. Being over dependent on financial measures of performance has caused the managers of SMEs to emphasize on the results of past actions instead of focusing on the factors which ensure success. Due to their lagging nature, managers who rely on financial measures are only able to obtain information of the results of previous activities; this means that they do not have any forward-looking information or indication of future performance.

From this perspective, non-financial performance measures could be better indicators of future financial performance since they provide an otherwise unavailable forward-looking information regarding business activities and financial results that have an impact on business performance. For instance, a measure of customer satisfaction could give an indication of future cash flow that would not be available via other means (Maduekwe \& Kamala, 2016).

Enhanced performance in respect of operations is of interest if it has an effect on organization's competitive position. Organizations that can offer exceptional value and/or lower prices will increase customer satisfaction and loyalty, and this could potentially increase their market share and maximize their profitability (Feng \& Wang, 2000). Operational performance involves structuring all business units within an organization to facilitate cooperation between these units in an effort to achieve core business goals. Saleh et al. (2018) defined operational performance as a performance that is linked to the internal operations of an organization, for instance productivity, product quality, and customer satisfaction.

\section{Conceptual Framework and Hypotheses}

An understanding of how entrepreneurial leadership and learning orientations influence the performance of SMEs is particularly important for several reasons. Most early studies focused on the experiential learning of individual entrepreneurs as a process for developing internal and external entrepreneurial venture and growth. Of late, however, researchers are focusing more on organizations as collective entities and are seeking to better understand how SMEs can learn and be involved in entrepreneurial activities to achieve sustainable entrepreneurship. Scholars are striving to gain a greater understanding of the entrepreneurial actions and learning processes within SMEs. It should be noted that the findings of previous studies clearly show that greater degree of failure occurs in the first few years of a venture start-up. Hence, learning orientations is crucial in 
providing continuous information regarding organisation's resources, abilities, and skills to fill the gap in internal environment to increase the organization ability to achieve the external request and align with entrepreneurial strategy (Allameh \& Khalilakbar, 2018).

\subsection{The Relationship Between Entrepreneurial Leadership and Organizational Performance}

Several previous studies have demonstrated the connection between entrepreneurial leadership and organizational performance. This connection was investigated using different types of research methods, including the meta-analysis, empirical, and conceptual methods. These studies, the empirical studies, were able to demonstrate a direct relationship between the two variables. The empirical studies have clearly identified how entrepreneurial leadership generate successful outcomes and have linked its influence on the proliferation of small- and medium-sized enterprises (SMEs) (Koryak et al., 2015). In this regard, Rahim et al. (2015) examined the relationship between entrepreneurial leadership and organizational performance with Malaysian SMEs. The researchers found that entrepreneurial leadership had a positive effect on organizational performance. Moghaddam (2015) suggested that organizations must be innovative and proactive in order to be able to achieve their missions and goals; to be specific, they have to practice organizational entrepreneurship. Based on discussion above, the previous studies support the relationship between entrepreneurial leadership and organizational performance. Therefore, the following hypothesis is proposed.

$\mathbf{H}_{01}$ : There is a positive effect of entrepreneurial leadership on organizational performance in SMEs.

\subsection{The Relationship Between Learning Orientation and Organizational Performance}

Learning orientation is essentially the acceptance of a learning process and change in order to generate and implement knowledge throughout an organization. Learning orientation has been extensively studied in the literature considering its strong influence on organizations. Researchers have been studying learning orientation as a source of competitive advantage that ultimately result in continuous enhanced performance (Shariff et al., 2017). Organizations with a high level of learning orientation have been shown to have superior performance in contrast to organizations which have a low level of learning orientation; this is especially true in a highly unpredictable competitive environment. However, scholars believe that the topic of learning orientation and performance has yet to be fully investigated (Wahab \& Mahmood, 2015). Through reviewing critically, the existing literature on learning orientation and organizational performance, the researchers noticed that, there was a multiplicity of opinions and results about the nature of this relationship. Several researches have emphasized the direct and positive relationship between learning orientation and organizational performance (e.g. Lestari, et al., 2018; Nikraftar \& Momeni, 2017; Kalmuk \& Acar, 2015). It is worth noting that a small number of studies have proven an indirect relationship; these studies have emphasized that innovation performance is influenced by learning orientation and this eventually enhances organizational performance. Additionally, some studies found that, there was no significant influence of learning orientation on organizational performance for example Wolff et al. (2015) were not able to identify any relationship between learning orientation and better performance of firms. Similarly, Suliyanto and Rahab (2012) investigated the connection between learning orientation and firm performance and concluded that firm performance was not positively influenced by learning orientation. Considering this, the present study aims to examine the effect of learning orientation on organizational performance in the context of Kuwaiti SMEs. Therefore, this study postulates the following hypothesis:

H02: There is a positive effect of learning orientation on organizational performance in SMEs.

\subsection{The Relationship Between Innovation Capacity and Organizational Performance}

Innovation capacity is a well-known factor in strategic management literature improves organizational performance. Rosenbusch et al. (2011) employed meta-analysis techniques to design 42 empirical studies that involved 21,270 firms to obtain evidence which affirm the relationship between innovation and performance. The focus of their research was on SMEs. Results show that innovation had a beneficial effect on the performance of organizations. The study also identified four factors which influence the relationship between innovation and performance. It was apparent that firms with high level of innovation capacity could create and develop new ideas and transform these ideas into a process, products, and services (Ilori et al., 2017; Kadar et al., 2014), would have the ability to maintain the position in the market that could lead to competitive advantages and superior performance (Kadar et al., 2014; Antunes et al., 2017). Consequently, the following hypothesis is suggested:

Ho3: There is a positive effect of innovation capacity on organizational performance in SMEs.

\subsection{The Relationship Between Entrepreneurial Leadership, Innovation Capacity, and Organizational Performance}

Entrepreneurship, innovation capacity and performance issues in SMEs are becoming increasingly important in ensuring the delivery of better services and products to consumers, with the ultimate objective of enhancing quality of life and nurturing better and stronger communities. Several studies found that, leaders who engage in entrepreneurial behaviors have the ability to direct employees toward identifying and exploiting opportunities and are more likely to foster innovative behavior among employees with higher levels of creative self-efficacy (Newman et al., 2018; Bagheri, 2017; Chen et al., 2014). Yusnita and 
Wahyudin (2017) suggested that, increased innovation is determined by the human resources (entrepreneurial leadership) owned by the organization. The results of this study showed that, entrepreneurial leadership variables had positive and direct influence on innovation capacity. In the light of this, innovation is an organization's output on account of drawing on their resourcefulness in terms of knowledge, information and experience. Hence, the critical factors ensuring the success of an innovation are knowledge and effectiveness of entrepreneurial leadership.

Huang et al. (2014) empirically showed that innovation (exploratory \& exploitative) mediates the relationship between entrepreneurial leadership and performance in in Chinese new ventures. Part of the limitations provided by Huang et al. (2014) is that future research should be conducted on the relationships among the entrepreneurial leadership, innovation, and performance in different contexts. Sethibe and Steyn (2015) in a review called for more empirical research that highlights the mediating effect of the nature of innovation on the relationship between leadership and organizational performance. In addition, according to Arshi and Viswanath, (2013) entrepreneurial leadership and innovation contracts are a new field and have not been tested in the Arab world; there is virtually no studies that can be used by organization leaders as a reference point. As a response to the suggestions of Arshi \& Viswanath, (2013), Huang et al. (2014) and Sethibe et al. (2015), in addition to the call for more in-depth empirical research that investigates entrepreneurial leadership in SMEs (Leitch \& Volery, 2017), this study will establish the mediating effect of innovation capacity between entrepreneurial leadership and organizational performance of SMEs. Thus, this study proposes the mediating hypothesis as follow:

Ho4: Innovation capacity mediates the relationship between entrepreneurial leadership and organizational performance of SMEs.

\subsection{The Relationship Between Learning Orientation, Innovation Capacity, and Organizational Performance}

Learning orientation (LO) is a significant in achieving superior organizational performance (Hussain et al., 2018). Also, is a significant factor that contributes to the success of innovation (Xian et al., 2018), and is an important source of competitive advantage for firms (Tajeddini, 2016). It is obvious that firms having higher innovation capacity can respond faster to environmental pressures (Gomes \& Wojahn, 2017; Herman et al., 2016), and therefore they have superior performance (Lestari et al., 2018).

The literature has so far found evidence that LO has a direct positive impact with organizational performance (Beneke et al., 2016; Lestari et al., 2018). However, the link between LO and performance remain empirically inconclusive because some studies found that direct influence of LO on organizational performance is not significant (Gomes \& Wojahn, 2017) including SMEs (Beneke et al., 2016), and must pass through intermediate variables that may intervene between LO and performance (Serna et al., 2016; Vij \& Farooq, 2015).

From the earlier discussions, it can be assumed that learning orientation positively influences innovation capacity. Some studies reveal that, learning orientation effect positively on organizational performance of SMEs (Lestari et al., 2018). In addition, several articles found that, organisation's innovation capacity effects performance in a positive way (Sözbilir, 2018). Based on that, learning orientation allows the organization to develop abilities and skills that improve innovation capacity and that innovation is what positively affects the organizational performance (Serna et al., 2016). Thus, this study proposes the mediating role of innovation capacity on the relationship between learning orientation and organizational performance as follow:

Ho5: Innovation capacity mediates the relationship between learning orientation and organizational performance of SMEs.

The findings of previous studies that are related to the variables used in the present study are used as a basis to develop a conceptual framework that is underpinned by the resource based view theory which claims that the organization performance is dynamically influenced by its existing internal resources and abilities. This statement is since an organization could achieve a superior performance over its rivals through efficient use of its resources. Hence, the proposed model will show the relationship between the four variables and their influences on Kuwait's SMEs. These variables are classified into three categories: (1) independent variables: entrepreneurial leadership / learning orientation; (2) dependent variable: organizational performance; and (3) mediating variable: innovation capacity (as shown in Fig. 1). The findings of previous studies have clearly shown that entrepreneurial leadership, learning orientation, and innovation capacity have direct effects on organizational performance. Furthermore, this research contributes to the existing body of knowledge by developing a conceptual framework for examining the mediating effect of innovation capacity on the relationship between entrepreneurial leadership, learning orientation and organizational performance, in order to give a deeper understanding regarding this relationship. The framework concludes that the implementation of each constructs would result in a beneficial impact on the organizational performance of SMEs in Kuwait. Therefore, managers should focus on formulating constructs that ensure better organizational performance. 


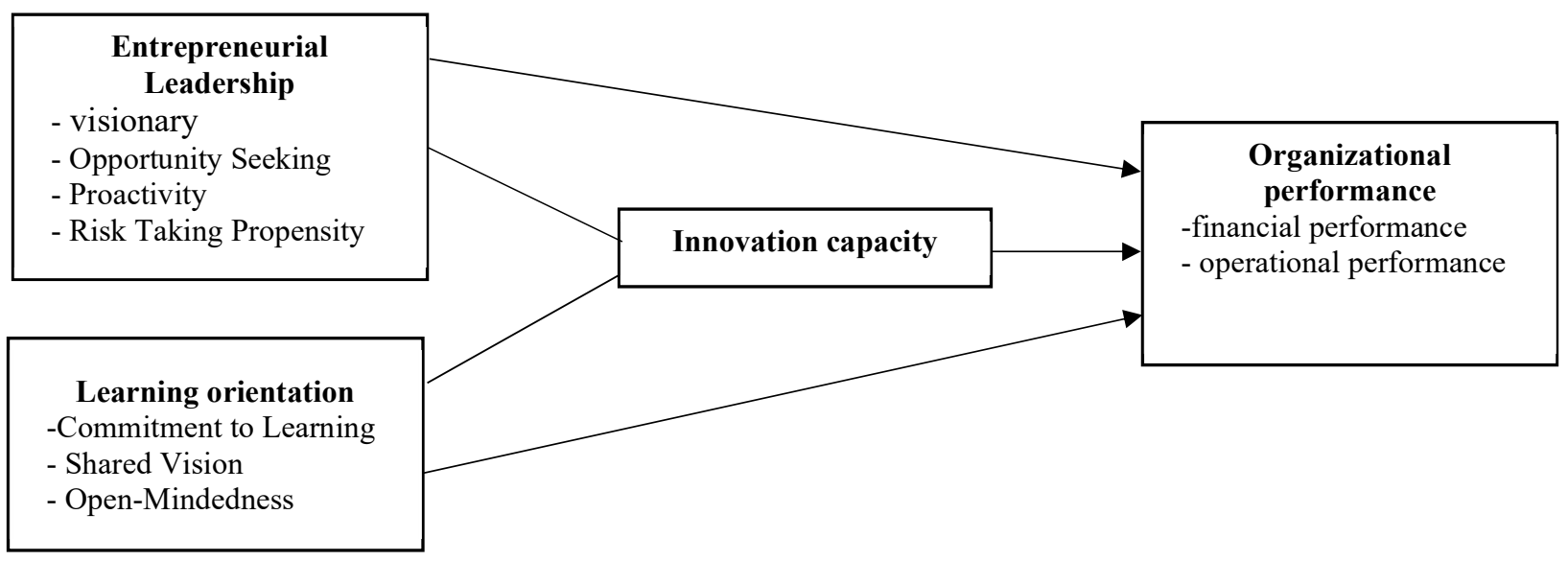

Fig. 1. Conceptual framework

\section{Methodology}

This study used a quantitative approach and tested a structural model using variance based structural equation modelling. This research conducted a survey by administering a standard questionnaire as the primary data collection method. The questionnaire written in both Arabic and English. A five-point Likert scale which ranged from strongly disagree to strongly agree was used. The target population of this research was the owners and CEOs of Kuwait's SMEs, and the sample was identified using a simple random sampling method. The data was gathered through face to face survey. The questionnaire was distribution among 500 owners and CEOs out of them 392 questionnaires were returned. On performing the data cleaning 8 of the questionnaires were not found to be useable hence the useable data was of 384 . The preliminary data analysis was performed using SPSS so that the issue such as missing values, outliers and non-normality of the data can be addressed. The main analysis was accomplished using Smart PLS 3. The measurement model was assessed by looking at the values of reliability and validity while the hypotheses were tested using bootstrapping method for the assessment of significance of the claimed relationships.

\subsection{Data Analysis}

The current research used structural equation modelling (SEM) using the partial least square technique which is variance based structural equation modelling technique and performs well with the small sample size and assumes the data is not normally distributed (Hair et al., 2018). This technique is being common among management and leadership research. This method is very much useful for the models having multiple relationships and focus on predicting and testing a theory (Hair et al., 2018). The method allows to test the hypothetical relationships simultaneously (Garson, 2016). The model along with items is presented below in Fig. 2.

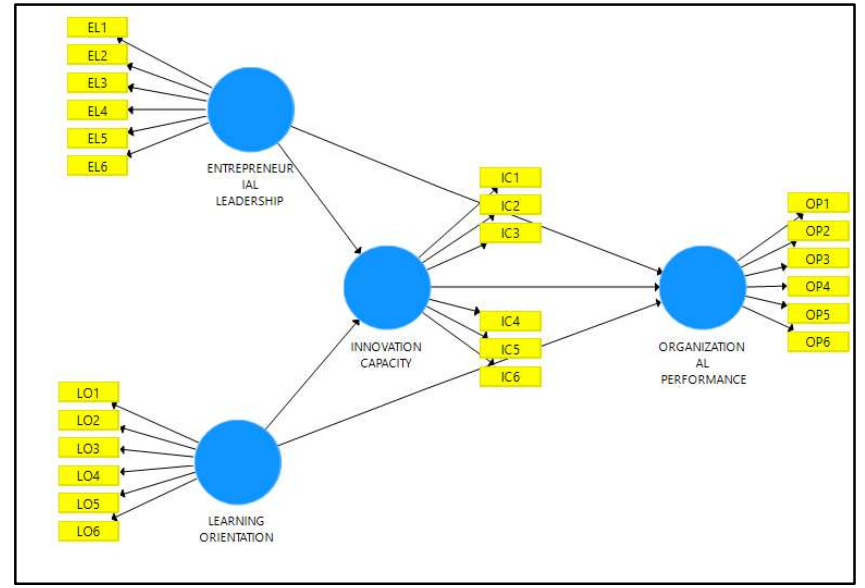

Fig. 2. Study Model 


\subsection{Model Assessment}

While looking at the results of the model one can notice the values of reliability and validity of the model. The assessment of the measurement model indicates the validity and reliability of the model having all alpha values to be greater than 0.7 supporting reliability of the constructs as shown in Table 1 as follows. The table also presents the values of average variance extracted for each construct showing the convergent validity. The threshold value for AVE is 0.5 all values exceed the value of 0.5 showing an enough level of convergent validity of the items towards their particular constructs. The values for Heterotrait-Monotrait Ratio of Correlations (HTMT) were used to examine the discriminant validity of the constructs (Henseler et al., 2016). The values for HTMT should be less than 0.9. In the case of present study all values are less than 0.9 see table below. Moreover, the outer loadings of all the items are also presented in the table.

Table 1

The Outer Loadings, Reliability and Validity Measures

\begin{tabular}{|c|c|c|c|c|c|}
\hline Construct & Item & Loading & $\begin{array}{l}\text { Composite } \\
\text { reliability }\end{array}$ & $\begin{array}{c}\text { Cronbach's } \\
\operatorname{alpha}(\alpha)\end{array}$ & $\begin{array}{c}\text { Average } \\
\text { variance } \\
\text { extracted (AVE) }\end{array}$ \\
\hline \multirow[t]{6}{*}{ Entrepreneurial Leadership } & EL1 & 0.794 & 0.939 & 0.920 & 0.719 \\
\hline & EL2 & 0.866 & & & \\
\hline & EL3 & 0.796 & & & \\
\hline & EL4 & 0.890 & & & \\
\hline & EL5 & 0.826 & & & \\
\hline & EL6 & 0.908 & & & \\
\hline \multirow[t]{6}{*}{ Learning Orientation } & LO1 & 0.925 & 0.968 & 0.962 & 0.834 \\
\hline & $\mathrm{LO} 2$ & 0.885 & & & \\
\hline & LO3 & 0.903 & & & \\
\hline & LO4 & 0.892 & & & \\
\hline & LO5 & 0.934 & & & \\
\hline & LO6 & 0.939 & & & \\
\hline \multirow[t]{6}{*}{ Innovation Capacity } & IC1 & 0.902 & 0.966 & 0.958 & 0.826 \\
\hline & $\mathrm{IC} 2$ & 0.859 & & & \\
\hline & IC3 & 0.898 & & & \\
\hline & $\mathrm{IC} 4$ & 0.923 & & & \\
\hline & IC5 & 0.932 & & & \\
\hline & IC6 & 0.937 & & & \\
\hline \multirow[t]{6}{*}{ Organizational Performance } & OP1 & 0.864 & 0.956 & 0.945 & 0.785 \\
\hline & OP2 & 0.819 & & & \\
\hline & OP3 & 0.896 & & & \\
\hline & OP4 & 0.907 & & & \\
\hline & OP5 & 0.910 & & & \\
\hline & OP6 & 0.914 & & & \\
\hline
\end{tabular}

Table 2

Discriminant Validity (HTMT)

\begin{tabular}{|c|c|c|c|c|}
\hline & Entrepreneurial Leadership & Innovation Capacity & Learning Orientation & Organizational Performance \\
\hline \multicolumn{5}{|l|}{ Entrepreneurial Leadership } \\
\hline Innovation Capacity & 0.342 & & & \\
\hline Learning Orientation & 0.375 & 0.565 & & \\
\hline Organizational Performance & 0.424 & 0.569 & 0.497 & \\
\hline
\end{tabular}

Once the measurement model is run and all the conditions for the validity and reliability of the constructs are satisfied, we run the bootstrapping for testing the structural model. This procedure allows us to test the significance of each direct and indirect relationship presented in the study. The study has five hypotheses. Three of them are associated with direct relationships while two are mediated relationships. The first three rows present the results of $\mathrm{H}_{1}, \mathrm{H}_{2}$ and $\mathrm{H}_{3}$ representing the relationship between entrepreneurial leadership and organizational performance, learning orientation and organizational performance and innovation capacity and organizational performance and the two hypotheses regarding the mediated relationships are shown in row 4 and 5. The results are presented in Table 3 as below.

\section{Table 3}

Hypotheses Testing for the Direct and Mediating Relationships

\begin{tabular}{|c|c|c|c|}
\hline Relationships & Path Coefficient & T Statistics & P Values \\
\hline H1:Entrepreneurial Leadership $\rightarrow$ Organizational Performance & 0.210 & 3.373 & 0.001 \\
\hline H2: Learning Orientation $\rightarrow$ Organizational Performance & 0.202 & 2.911 & 0.004 \\
\hline H3: Innovation Capacity $\rightarrow$ Organizational Performance & 0.367 & 5.321 & 0.000 \\
\hline Entrepreneurial Leadership $\rightarrow$ Innovation Capacity $\rightarrow$ Organizational Performance & 0.057 & 2.555 & 0.011 \\
\hline Learning Orientation $\rightarrow$ Innovation Capacity $\rightarrow$ Organizational Performance & 0.179 & 4.325 & 0.000 \\
\hline
\end{tabular}


The results of Table 3 show the path coefficient of entrepreneurial leadership and organizational performance is 0.210 showing a positive relationship while the p-value 0.001 is less than 0.05 showing the relationship is significant hence $\mathrm{H}_{1}$ is supported. The table shows the relationship between learning orientation and organizational performance to be positive with path coefficient 0.202 and p-value 0.004 which is less than 0.05 showing a significant and positive relationship hence $\mathrm{H}_{2}$ of the study is also supported. In the similar fashion, the relationship between innovation capacity and organizational performance was also found to be supported with path coefficient 0.367 and p-value 0.000 which was less than 0.05 . Hence the $\mathrm{H}_{3}$ of the study was also found to be supported. The $\mathrm{H}_{4}$ and $\mathrm{H}_{5}$ of the study represent the mediation of innovation capacity in the relationship between entrepreneurial leadership and organizational performance and learning orientation and organizational performance respectively. The path coefficient of entrepreneurial leadership $\rightarrow$ innovation capacity $\rightarrow$ organizational performance is 0.057 with the p-value 0.011 which is less than 0.05 . Hence, supporting the $\mathrm{H}_{4}$ indicating the significant mediating role of innovation capacity in relationship between entrepreneurial leadership and organizational performance. The path coefficient of learning orientation $\rightarrow$ innovation capacity $\rightarrow$ organizational performance is 0.179 with the p-value 0.000 which is less than 0.05 . Hence, supporting the $\mathrm{H}_{5}$ indicating the significant mediating role of innovation capacity in relationship between learning orientation and organizational performance. Fig. 3 and Fig. 4 below show the path coefficients for direct and indirect effects along with $\mathrm{R}^{2}$ of the constructs in the PLS model.

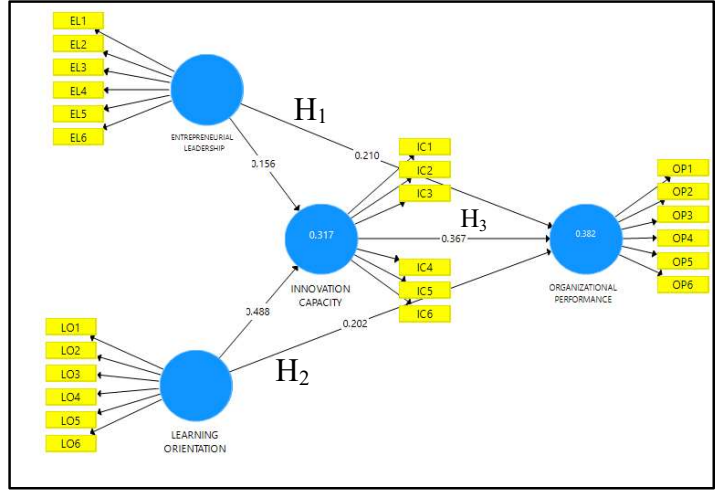

Fig. 3. Path Coefficients for Direct Effects $\left(\mathrm{H}_{1}, \mathrm{H}_{2}\right.$ and $\left.\mathrm{H}_{3}\right)$

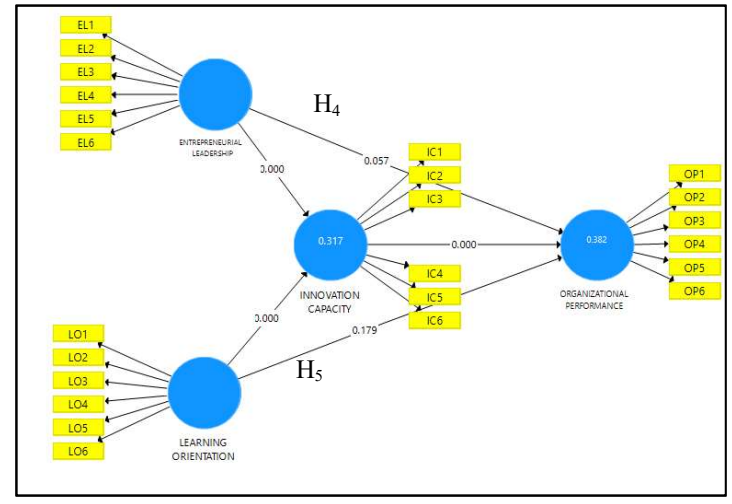

Fig. 4. Path Coefficient for Indirect Effects $\left(\mathrm{H}_{4}\right.$ and $\left.\mathrm{H}_{5}\right)$

\section{Discussion}

The study aimed to understand the direct implications of entrepreneurial leadership and learning orientation on organizational performance as well as with the mediation of innovation capacity. The results for all hypotheses were significant and hence were supported. The first hypothesis was concerned with the link between entrepreneurial leadership and organizational performance and this link was found to be positive. Researchers have been studying learning orientation as the driver of competitive advantage that eventually bring fort continuous enhanced performance (Shariff et al., 2017). The findings of the study have provided empirical support to the idea put forward by Shariff et al. (2017). Second hypothesis stated the link between learning orientation and organizational performance, and this link has been found to be a positive and significant one. Several studies have emphasized on the direct and positive relationship between learning orientation and organizational performance (e.g. Lestari, et al., 2018; Nikraftar \& Momeni, 2017; Kalmuk \& Acar, 2015). These works agree with the results concerning learning orientation and organizational performance. Strategic management literature has demonstrated that innovation capacity contributes on improving organizational performance. Firms with high levels of innovation have the capacity to create and develop new ideas and transform these ideas into processes, products, and services (Ilori et al., 2017; Kadar et al., 2014); these firms also have the ability to preserve their position in the market in a manner that ensures their competitive advantage and superior performance (Kadar et al., 2014; Antunes et al., 2017). The idea is supported by the empirical evidence provided by the current study on the beneficial effects of innovation capacity on organizational performance. Several studies have shown that leaders who engage in entrepreneurial behaviors have the ability to motivate employees to recognize and seize opportunities; these leaders would most probably nurture innovative behavior amongst employees and impart on higher levels of creative self-efficacy (Newman et al., 2018; Bagheri, 2017: Chen et al., 2014). Yusnita and Wahyudin (2017) suggested that higher levels of innovation are influenced by the human resources (entrepreneurial leadership) that are inherent in an organization and this in consequence leads to the better performance of the organizations. In the same vein, the current study tested the mediating effect of innovation capacity and was able to identify an indirect relationship between entrepreneurial leadership and organizational performance. The findings of a study conducted in the Chinese context by Huang et al. (2014) are consistent with the results of the current work. Several studies have shown that learning orientation has a beneficial impact on the organizational performance of SMEs (Lestari et al., 2018). In addition, several articles have pointed out that organisation's innovation capacity has a positive influence on the organisation's performance (Sözbilir, 2018). In this light, learning orientation provides organizations with the opportunity to develop abilities and skills that improve innovation capacity and that innovation positively affects organizational performance (Serna et al., 2016). Hence the outcomes of the present research have provided sufficient evidences that learning orientation and organizational performance were indirectly related with the 
mediating role of innovation capacity. This section of the article has presented a detailed discussion on the findings of the study. The next section will present the conclusion and limitations of the study.

\section{Conclusion}

In developing countries such as Kuwait, where regional orientation of entrepreneurship in on the increase, there is a need to strengthen support to SMEs. The study has found the positive and significant impact of entrepreneurial leadership and learning orientation on organizational performance. Moreover, the innovation capacity has also been found to be a significant mediator in the relationships. Based on the results of this study, it can be concluded that SMEs should embrace entrepreneurial leadership and improve their learning orientation in order to develop their abilities, competitive advantage, and performance, thereby ensuring their long-term success. This study has proven that entrepreneurial leadership facilitates the formulation of innovation strategy, processes, and skills, as well as organizing resources in order to coordinate them with the efforts to benefit from innovative opportunities. Learning orientation also helps organizations discontinue the utilization of current methods and processes in order to adopt more innovation practices. This paper has presented a conceptual framework which should attract the interest of practitioners and academia. The interaction of the variables highlighted in this paper can serve as a catalyst that promotes better SMEs performance in developing economies. Moreover, the outcome of this study brings with some beneficial implications to the owners and leaders of SMEs in general and in Kuwait in order to help them manage their organizations more effectively, thereby achieving higher levels of sustainability and competitiveness. In this context, the managers of SMEs are advised to give serious attention for developing innovativeness, the ongoing learning practice and entrepreneurial behavior, so as to ensure better performance of SMEs.

\section{Limitation and Future Research}

The study model only employed entrepreneurial leadership and learning orientation in the model to understand their role in organizational performance. However, there are more leadership traits that may impact on the organizational performance. Future researchers can bring those variables in the equation and understand the phenomenon in a much better way. Moreover, this study has developed a model which focused on the SMEs in Kuwait, and therefore there is a need for future studies to examine the framework of this study in the context of other countries and in different industries, such as the technological industry, in order to be able to generalize the results. Finally, future studies may investigate the direct effect of market orientation on organizational performance.

\section{References}

Ahmed, E. (2018). Organizational citizenship behaviors and it relation with organizational performance of administrative leaders in arab sports systems. Journal of American Science, 14(1). http:/www.jofamericanscience.org.

Allameh, S. M., \& Khalilakbar, R. (2018). Exploring the antecedents of innovation performance: the roles of entrepreneurial orientation, learning orientation and organisational learning. International Journal of Business Excellence, 14(4), 470.

Almatrooshi, B., Singh, S. K., \& Farouk, S. (2016). Determinants of organizational performance: a proposed framework. International Journal of Productivity and Performance Management, 65(6), 844-859.

Amin, M. (2015). The effect of entrepreneurship orientation and learning orientation on SMEs' performance: an SEM-PLS approach. Journal for International Business and Entrepreneurship Development, 8(3), 215-230.

Antunes, M. G., Quirós, J. T., \& Justino, M. D. R. F. (2017). The relationship between innovation and total quality management and the innovation effects on organizational performance. International Journal of Quality \& Reliability Management, 34(9), 1474-1492.

Arshi, T. A., \& Viswanath, S. (2013). Entrepreneurial leadership and innovation: An empirical study on organizational leadership characteristics and entrepreneurial innovation intensity. American Journal of Social Issues and Humanities, 3(5), 2276-6928.

Baba, Y. (2015). Does learning orientation matter for nonprofit organization performance? Empirical evidence from Ghana. Leadership \& Organization Development Journal, 36(3), 234-252.

Bagheri, A. (2017). The impact of entrepreneurial leadership on innovation work behavior and opportunity recognition in high-technology SMEs. The Journal of High Technology Management Research, 28(2), 159-166.

Beneke, J., Blampied, S., Dewar, N., \& Soriano, L. (2016). The impact of market orientation and learning orientation on organisational performance: A study of small to medium-sized enterprises in Cape Town, South Africa. Journal of Research in Marketing and Entrepreneurship, 18(1), 90-108.

Chavan, M. (2009). The balanced scorecard: a new challenge. Journal of Management Development, 28(5), $393-406$.

Chen, M. H. (2007). Entrepreneurial leadership and new ventures: Creativity in entrepreneurial teams. Creativity and Innovation Management, 16(3), 239-249.

Dereli, D. D. (2015). Innovation management in global competition and competitive advantage. Procedia-Social and behavioral sciences, $195,1365-1370$.

Garson, G. D. (2016). Partial least squares: Regression and structural equation models. Asheboro, NC: Statistical Associates Publishers. 
Greenberg, D., McKone-Sweet, K., \& Wilson, H. J. (2013). Entrepreneurial leaders: creating opportunity in an unknowable world. Leader to Leader, 2013(67), 56-62.

Gomes, G., \& Wojahn, R. M. (2017). Organizational learning capability, innovation and performance: study in small and medium-sized enterprises (SMES). Revista de Administração (São Paulo), 52(2), 163-175.

Gupta, V. K., \& Batra, S. (2016). Entrepreneurial orientation and firm performance in Indian SMEs: Universal and contingency perspectives. International Small Business Journal, 34(5), 660-682.

Gupta, V., MacMillan, I. C., \& Surie, G. (2004). Entrepreneurial leadership: developing and measuring a cross-cultural construct. Journal of Business Venturing, 19(2), 241-260.

Hair, J. F., Risher, J. J., Sarstedt, M., \& Ringle, C. M. (2019). When to use and how to report the results of PLS-SEM. European Business Review, 31(1), 2-24.

Henseler, J., Hubona, G., \& Ray, P. A. (2016). Using PLS path modeling in new technology research: updated guidelines. Industrial Management \& Data Systems, 116(1), 2-20.

Herman, H., Hady, H., \& Arafah, W. (2018). The influence of market orientation and product innovation on the competitive advantage and its implication toward Small and Medium Enterprises (UKM) performance. International Journal of Science and Engineering Invention, 4(08), 08-to.

Huang, S., Ding, D., \& Chen, Z. (2014). Entrepreneurial Leadership and Performance in C hinese New Ventures: A Moderated Mediation Model of Exploratory Innovation, Exploitative Innovation and Environmental Dynamism. Creativity and Innovation Management, 23(4), 453-471.

Hurley, R. F., \& Hult, G. T. M. (1998). Innovation, market orientation, and organizational learning: an integration and empirical examination. Journal of marketing, 62(3), 42-54.

Hussain, J., Shah, F. A., Rehman, W., \& Khan, Y. (2018). Learning orientation and performance: the interaction effect of entrepreneurial orientation. Pakistan Business Review, 19(4), 960-977.

Ilori, A. B., Lawal, A., \& Simeon-Oke, O. O. (2017). Innovations and innovation capability in palm kernel processing industry in southwestern Nigeria. International Journal of Innovation Science, 9(1), 102-114.

Jagdale, D., \& Bhola, S. S. (2014). Entrepreneurial leadership and organizational performance with reference to rural small scale engineering industry in Pune district. Golden Research Thoughts, 4.

Kadar, M., Moise, I. A., \& Colomba, C. (2014). Innovation management in the globalized digital society. Procedia-Social and Behavioral Sciences, 143, 1083-1089.

Kalmuk, G., \& Acar, A. Z. (2015). The effect of quality orientation and learning orientation on firm performance. Pressacademia, 2(4), 455-455.

Koryak, O., Mole, K. F., Lockett, A., Hayton, J. C., Ucbasaran, D., \& Hodgkinson, G. P. (2015). Entrepreneurial leadership, capabilities and firm growth. International Small Business Journal, 33(1), 89-105.

Kozłowski, R. (2010). Entrepreneurial Leadership and Its Influence as an Innovation Catalyst in Modern Management. Współczesne Zarządzanie, (4), 55-62.

Kraśnicka, T. G., Głód, W., \& Pośpiech, M. (2016). Management Innovation and Its Measurement. Journal of Entrepreneurship, Management and Innovation, 12(2), 95-122.

Leitch, C. M., \& Volery, T. (2017). Entrepreneurial leadership: Insights and directions. International Small Business Journal, 35(2), 147-156.

Lestari, E. R., Ardianti, F. L., \& Rachmawati, L. (2018, March). Firm performance model in small and medium enterprises (SMEs) based on learning orientation and innovation. In IOP Conference Series: Earth and Environmental Science (Vol. 131, No. 1, p. 012027). IOP Publishing.

Maduekwe, C. C., \& Kamala, P. (2016). Performance measurement by small and medium enterprises in Cape Metropolis, South Africa. Problems and Perspectives in Management, 14(2), 46-55.

Meyer, H. H., \& Paulsen, B. (2018). Public Innovation Management Support in Rural Areas: the ARTIE Case in Germany. In German-Turkish Perspectives on IT and Innovation Management (pp. 109-121). Springer Gabler, Wiesbaden.

Mishra, P., \& Misra, R. K. (2017). Entrepreneurial Leadership and Organizational Effectiveness: A Comparative Study of Executives and Non-executives. Procedia Computer Science, 122, 71-78.

Moghaddam, J. Y., Khorakian, A., \& Maharati, Y. (2015). Organizational Entrepreneurship and its Impact on the Performance of Governmental Organizations in the City of Mashhad. Procedia - Social and Behavioral Sciences, 169(August 2014), $75-87$.

Nagano, M. S., Stefanovitz, J. P., \& Vick, T. E. (2014). Innovation management processes, their internal organizational elements and contextual factors: An investigation in Brazil. Journal of Engineering and Technology Management, 33, 6392.

Newman, A., Herman, H. M., Schwarz, G., \& Nielsen, I. (2018). The effects of employees' creative self-efficacy on innovative behavior: The role of entrepreneurial leadership. Journal of Business Research, 89, 1-9.

Nikraftar, T., \& Momeni, S. (2017). The effects of entrepreneurial orientation, market orientation and learning orientation on performance of ICT business. International Journal of Management Concepts and Philosophy, 10(4), 378-391.

Orlitzky, M., Schmidt, F. L., \& Rynes, S. L. (2003). Corporate social and financial performance: A meta-analysis. Organization studies, 24(3), 403-441.

Oura, M. M., Zilber, S. N., \& Lopes, E. L. (2016). Innovation capacity, international experience and export performance of SMEs in Brazil. International Business Review, 25(4), 921-932. 
Palalic, R. (2017). The phenomenon of entrepreneurial leadership in gazelles and mice: A qualitative study from Bosnia and Herzegovina. World Review of Entrepreneurship, Management and Sustainable Development, 13(2-3), 211-236.

Rahim, H. L., Zainal Abidin, Z., Mohtar, S., \& Ramli, A. (2015). The effect of entrepreneurial leadership towards organizational performance. International Academic Research Journal of Business and Technology.

Rae, D. (2016). Developing entrepreneurial leadership: the challenge for sustainable organisations. International Journal of Work Innovation, 2(1), 76-100.

Rosenbusch, N., Brinckmann, J., \& Bausch, A. (2011). Is innovation always beneficial? A meta-analysis of the relationship between innovation and performance in SMEs. Journal of business Venturing, 26(4), 441-457.

Saleh, R. A., Sweis, R. J., \& Mahmoud Saleh, F. I. (2018). Investigating the impact of hard total quality management practices on operational performance in manufacturing organizations: Evidence from Jordan. Benchmarking: An International Journal, 25(7), 2040-2064.

Serna, M. D. C. M., Martínez, J. E. V., \& Martínez, J. V. (2016). The impact of learning orientation on innovation and performance in smes in México. International Review of Management and Business Research, 5(1), 48.

Sethibe, T., \& Steyn, R. (2015). The relationship between leadership styles, innovation and organizational performance: A systematic review. South African Journal of Economic and Management Sciences, 8(3).

Shariff, M. N. M., Ahmad, N. R., \& Hafeez, M. H. (2017). Moderating role of access to finance on entrepreneurial orientation, market orientation, learning orientation and SMEs performance of gem and jewelry industry in Thailand. Journal of Business and Social Review in Emerging Economies, 3(1), 109-120.

Haroon, U., \& Shariff, M. N. M. (2016). The interplay of innovation, TQM practices and SMEs performance in Pakistan: moderating effects of knowledge inertia and external environment. Economics and Law, 9(2), 57-62.

Şimşit, Z. T., Vayvay, Ö., \& Öztürk, Ö. (2014). An outline of innovation management process: building a framework for managers to implement innovation. Procedia-Social and Behavioral Sciences, 150, 690-699.

Sinkula, J.M., Baker, W.E. and Noordewier, T.A. (1997). "Framework for market-based organizational learning: linking values, knowledge, and behaviour", Academy of Marketing Science, 25(4), 305-318.

Sözbilir, F. (2018). Innovation Capacity and Innovation Performance in Terms of Educational Level of Managers. İsletme Araştırmaları Dergisi, 10(2), 1-12.

Strobl, A., Bauer, F., \& Matzler, K. (2018). The impact of industry-wide and target market environmental hostility on entrepreneurial leadership in mergers and acquisitions. Journal of World Business. https://doi.org/10.1016/j.jwb.2018.03.002

Tajeddini, K. (2016). Analyzing the influence of learning orientation and innovativeness on performance of public organizations: The case of Iran. Journal of Management Development, 35(2), 134-153.

Tomal, D. R., \& Jones, K. J. (2015). A comparison of core competencies of women and men leaders in the manufacturing industry. The Coastal Business Journal, 14(1), 13-25.

Suliyanto, S., \& Rahab, R. (2012). The role of market orientation and learning orientation in improving innovativeness and performance of small and medium enterprises. Asian Social Science, 8(1), 134.

Vij, S., \& Farooq, R. (2015). The relationship between learning orientation and business performance: do smaller firms gain more from learning orientation?. IUP Journal of Knowledge Management, 13(4).

Wahab, A., \& Mahmood, R. (2015, November). Effect of learning orientation and self-efficacy on performance of university leaders: entrepreneurial leadership as a mediator. th Annual Convention of Japanese Association of Administrative Science (JAAS) held atAichi University, Nagoya Campus, Japan.

Wheelen, T.L., \& Hunger, J.D. (2010). Strategic Management and Business Policy. Pearson, Upper Saddle River.

Wolff, J. A., Pett, T. L., \& Ring, J. K. (2015). Small firm growth as a function of both learning orientation and entrepreneurial orientation: An empirical analysis. International Journal of Entrepreneurial Behavior \& Research, 21(5), 709-730.

Xian, K. J., Sambasivan, M., \& Abdullah, A. R. (2018). Impact of market orientation, learning orientation, and supply chain integration on product innovation. International Journal of Integrated Supply Management, 12(1-2), 69-89.

Yang, C. C. (2018). The effectiveness analysis of the practices in five quality management stages for SMEs. Total Quality Management \& Business Excellence, 1-23. https://doi.org/10.1080/14783363.2018.1456010

Yunoh, M. N. M., \& Ali, K. A. M. (2015). Total quality management approach for Malaysian SMEs: Conceptual framework. International Journal of Business and Social Science, 6(1),152-161.

Yusnita, M., \& Wahyudin, N. (2017). Entrepreneurial leadership through innovation capacity as an effort to increase competitive advantage of UMKM in Era of ASEAN economic community (MEA)(Micro Business Study in Kabupaten Bangka). Integrated Journal of Business and Economics, 1(1), 10-18.

Zehir, C., Can, E., \& Karaboga, T. (2015). Linking entrepreneurial orientation to firm performance: the role of differentiation strategy and innovation performance. Procedia-Social and Behavioral Sciences, 210, 358-367.

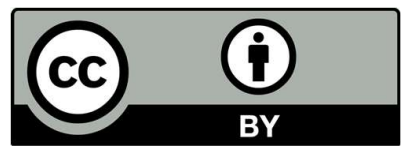

(C) 2020 by the authors; licensee Growing Science, Canada. This is an open access article distributed under the terms and conditions of the Creative Commons Attribution (CCBY) license (http://creativecommons.org/licenses/by/4.0/). 